\title{
Prevalência de anticorpos antifosfolipides em diabéticas gestacionais e pré-gestacionais
}

\author{
Antiphospholipid antibodies in gestational and pregestational diabetic women \\ Patricia Moretti Rehder ${ }^{1}$, Belmiro Gonçalves Pereira ${ }^{2}$, Egle Cristina Couto ${ }^{3}$, \\ Eliana Amaral'2 , Mary Ângela Parpinelli
}

\section{RESUMO}

Objetivo: identificar e descrever a prevalência de anticorpos antifosfolípides (anticorpo anticardiolipina e anticoagulante lúpico) em gestantes diabéticas. Métodos: estudo prospectivo de prevalência, realizado no período de julho de 2003 a março de 2004. Foram estudadas 56 gestantes diabéticas gestacionais e pré-gestacionais que ingressaram ao pré-natal e aceitaram participar do estudo. Nenhuma gestante foi excluída. Se um ou outro anticorpo estivesse presente, a gestante seria tratada com heparina e ácido acetilsalicílico. Foram caracterizados os perfis da gestante, a evolução da gestação e o recém-nascido. Resultados: foram diagnosticados anticorpos antifosfolípides em apenas quatro gestantes das 56 estudadas, o que representou prevalência de 7\% (IC 95\% - 0,1-13,9). Nas gestantes diabéticas com anticorpos antifosfolípides a duração do diabetes foi de cinco anos ou mais. A idade variou de 27 a 38 anos, sendo uma primigesta, outra secundigesta e as outras duas multíparas. As gestantes com anticorpos antifosfolípides, que foram tratadas, tiveram recém-nascidos vivos, de termo, cujos pesos variaram entre $2.650 \mathrm{~g} \mathrm{e} 4.000 \mathrm{~g}$. Conclusão: a prevalência de anticorpos antifosfolípides em gestantes diabéticas gestacionais é baixa, e similar à população geral de grávidas. Está prevalência aumenta quando a gestante é diabética prégestacional.

PALAVRAS-CHAVE: Gravidez de alto risco; Gravidez em diabéticas; Anticorpos antifosfolipídeos; Síndrome antifosfolipídica; Diabete mellitus

\section{ABSTRACT}

Purpose: to diagnose and treat diabetic pregnant women with antiphospholipid antibodies and to describe the gestational and perinatal results. Methods: we evaluated 56 gestational and pregestational diabetic women who were attended at one specialized prenatal care unit, between July 2003 and March 2004. All of them had a blood test to quantify antiphospholipid antibodies. If positive, they were treated with heparin and aspirin at low doses and the usual treatment for diabetes. We calculated the prevalence and $95 \%$ confidence interval for all and also those for the pregestational ones. The characteristics of the pregnancies and the newborns are described. Results: antiphospholipid antibodies prevalence among the diabetic pregnant women was 7\% (95\% CI - 0.1 to 13.9). Among pregestational diabetic women it was $12 \%$ (95\% CI - 0.2 to 23.3$)$. Among the diabetic women with antiphospholipid antibodies the duration of disease was five years or more. Maternal age in positive antiphospholipid antibodies diabetics ranged from 27 to 38 years; one was primiparous, another was secundiparous and two were multiparous. Conclusion: antiphospholipid antibodies prevalence in diabetic pregnant women was similar to that in the general population and lower than that of the pregestational diabetic women.

KEYWORDS: High-risk pregnancy; Pregnancy in diabetes; Antibodies, antiphospolipid; Antiphospholipid syndrome; Diabetes mellitus

\footnotetext{
Departamento de Tocoginecologia - Universidade Estadual de Campinas - UNICAMP - Campinas (SP), Brasil.

1 Médica Contratada na Área de Tocoginecologia Funcamp/CAISM - Campinas (SP), Brasil.

2 Docente de Tocoginecologia da Faculdade de Ciências Médicas - Universidade Estadual de Campinas - UNICAMP - Campinas (SP), Brasil.

3 Médica contratada na Área de Tocoginecologia CAISM - Universidade Estadual de Campinas - UNICAMP - Campinas (SP), Brasil.

Correspondência: Patricia Moretti Rehder

Rua: Alexander Fleming, 101 Cidade Universitária - 13083-881 - Campinas - SP - Telefone: (11) 3788-9232/ Fax: (11) 3788-9304 - e-mail: patyrehder@ig.com.br; belmiro@caism.br
} 


\section{Introdução}

Diabete melito é doença metabólica crônica, caracterizada predominantemente por aumentos da glicemia e, secundariamente, por alterações dos vasos sangüineos que podem causar lesões viscerais. A gestação em mulheres diabéticas envolve importantes riscos maternos e fetais devido a cetoacidose, infecções, hipertensão arterial, abortos, malformações fetais e mortalidade perinatal $^{1,2}$. Com o controle dos níveis glicêmicos maternos com dieta, exercícios, insulina, associado com a monitorização do feto e cuidados intensivos ao recém-nascido, a morbidade perinatal foi reduzida de $65 \%$ para taxas inferiores a $2,5 \%{ }^{3}$.

A morbidade materna e fetal associada ao diabete melito pré-gestacional continua sendo problema freqüente, pois estas gestantes apresentam maior incidência de pré-eclâmpsia, prematuridade, restrição de crescimento fetal e óbito perinatal. Estas condições podem estar relacionadas com maior incidência de vasculopatias nestas mulhe$\mathrm{res}^{4,5}$. Há muito se sabe que o tempo de duração do diabete tem relação direta com a ocorrência de doença vascular e pode estar associada a maus resultados gestacionais e perinatais. No diabete gestacional estes eventos são mais raros, porém mais freqüentes que na população geral de gestantes sem diabete d,6-9. $^{3,6}$.

Entender a fisiopatologia das complicações em diabéticas metabolicamente bem controladas permanece desafio a ser resolvido. A associação com alterações vasculares pode ser uma explicação ${ }^{10}$. Entretanto, o diagnóstico destas alterações, em sua fase inicial, pode ser muito dificil. Possível forma de detecção, descrita na literatura, pode ser a pesquisa de anticorpos antifosfolipides em gestantes diabéticas ${ }^{10-12}$.

Os anticorpos antifosfolípides são imunoglobulinas que reagem contra fosfolipides de membrana carregados negativamente. Quando esses anticorpos estão associados a trombose vascular e a complicações gestacionais tais como pré-eclâmpsia, aborto de repetição, restrição de crescimento intra-uterino e óbito fetal, caracterizam a sindrome antifosfolipides ${ }^{13}$. Estes anticorpos podem levar à redução da produção de prostaglandina pelas células endoteliais, aumento do tromboxano e diminuição da ativação da proteína $\mathrm{C}$, ocasionando vasoconstrição, que pode responder, em parte, pela hipertensão arterial materna e perdas fetais ${ }^{14-17}$.

A associação de anticorpos antifosfolípides em gestantes diabéticas aumenta o risco de complicação materno-fetal devido a estes anticorpos ocasionarem infartos placentários causando restrição de crescimento intra-uterino. As alterações metabólicas e vasculares responsáveis pela morbidade materno-fetal poderiam ser reduzidas nas gestantes diabéticas se o diabete estiver controlado adequadamente e os anticorpos antifosfolipides forem diagnosticados e, quando presentes, tra$\operatorname{tados}^{10,18}$.

A terapia proposta em gestantes diabéticas com anticorpos antifosfolípides inclui dieta e/ou insulina e exercícios para o controle metabólico do diabete, associado ao ácido acetilsalicílico em baixas doses (100 mg em 24 horas) e heparina de alto peso molecular (10.000 UI de 12 em 12 horas) ou de baixo peso molecular $(40 \mathrm{mg} / \mathrm{dia})^{19-21}$. Com este tratamento os resultados gestacionais e perinatais em gestantes diabéticas com anticorpos antifosfolipides seriam satisfatórios.

\section{Métodos}

Estudo prospectivo de prevalência e descritivo para a presença de anticorpos antifosfolípides em gestantes com diabete melito realizado no prénatal especializado do CAISM-Unicamp no periodo de julho de 2003 a março de 2004 . Foram selecionadas 56 gestantes com diagnóstico de diabete gestacional ou pré-gestacional. Todas as diabéticas que aceitaram participar foram submetidas à coleta de sangue para dosagem de anticorpos antifosfolípides (anticoagulante lúpico e anticorpo anticardiolipina). Se um ou outro anticorpo estivesse presente a gestante recebia tratamento anticoagulante com heparina e ácido acetilsalisílico, em associação ao tratamento para diabete melito. As variáveis estudadas incluíram: idade da gestante, paridade, idade gestacional de ingresso ao pré-natal, tempo de duração do diabete melito, controle do diabete, presença de hipertensão na gestação, hipertensão arterial crônica, índice de líquido amniótico, via de parto, peso do recémnascido, presença de malformação fetal, sofrimento fetal, evolução perinatal e morbidade perinatal (hipoglicemia fetal, insuficiência respiratória). Nenhuma gestante foi excluída do estudo.

O anticorpo anticardiolipina foi detectado pelo método de ELISA (enzyme-linked immunosorbent assay), com identificação de IgG e/ou IgM. A dosagem de anticoagulante lúpico foi realizada pelo método Dilute Russel Viper Venom Time, que ativa diretamente o fator X.

Após preencherem os critérios necessários para admissão e assinarem o Consentimento Livre e Esclarecido Pós-Informado, as gestantes fo- 
ram submetidas a uma entrevista para obtenção de informações sobre os dados clínicos necessários para o estudo. Na segunda consulta ao pré-natal, se positivo um e/ou outro anticorpo, a gestante era tratada e acompanhada até o parto.

Os dados foram analisados pelo cálculo de prevalência com intervalo de confiança de $95 \%$. As mulheres que apresentaram anticorpos antifosfolipides em qualquer título foram descritas. O estudo foi aprovado pelo Comitê de Ética e Pesquisa da FCM - UNICAMP. Os resultados foram descritos nas mulheres com anticorpos antifosfolipides presentes. Devido à baixa prevalência não foi possível avaliação estatística.

\section{Resultados}

Entre as 56 gestantes com diabete melito, a presença dos anticorpos antifosfolipides foi positiva em 7\% (IC 95\% - 0,1 a 13,9\%). As quatro gestantes portadoras de anticorpos antifosfolipides eram diabéticas pré-gestacionais, com cinco anos ou mais de evolução da doença. Considerando apenas as gestantes diabéticas pré-gestacionais, a prevalência de anticorpos antifosfolípides foi de $12 \%$ (IC 95\% - 0,2 a 23,3\%). Nas com mais de cinco anos de doença a prevalência encontrada foi de $25 \%$, com IC a 95\% entre 0,5-42,6 (Tabela 1).

Tabela 1 - Prevalência de gestantes portadoras de anticorpos antifosfolípides de acordo com o tempo de evolução do diabetes.

\begin{tabular}{lccc}
\hline \multicolumn{4}{c}{ Gestantes diabéticas } \\
& $\mathbf{n} / \mathbf{N}$ & $\%$ & IC $95 \%$ \\
\hline Com anticorpos antifosfolípides & $4 / 56$ & 7 & $0,1-13,9$ \\
Pré-gestacional & $4 / 33$ & 12 & $0,2-23,3$ \\
$>5$ anos & $4 / 16$ & 25 & $0,5-42,6$ \\
\hline
\end{tabular}

A idade das quatro gestantes portadoras de anticorpos antifosfolipides variou entre 27 e 38 anos. Apenas uma gestante era primigesta. Outra gestante havia tido seis gestações anteriormente, com uma cesárea por macrossomia, três abortos e um parto normal com recém-nascido pequeno para idade gestacional. A terceira gestante tinha uma cesárea anterior por sofrimento fetal agudo e a quarta gestante tinha seis gestações anteriores, sendo cinco partos normais, com apenas o último recém-nascido pequeno para idade gestacional, e um aborto.

As características do diabete melito são descritas na Tabela 2. Três gestantes tinham 10 anos de duração da doença. A medicação usada antes da gestação para controle do diabete melito em duas delas era anti-hiperglicemiante oral e nas outras duas, insulina NPH humana. Nenhuma delas apresentava hipertensão arterial prévia à gestação.

Tabela 2 - Características das gestantes diabéticas com anticorpos antifosfolípides: idade, duração da doença e tratamento.

\begin{tabular}{cccc}
\hline Caso & Idade & Duração & Controle \\
\hline 1 & 27 & 10 anos & Insulina \\
2 & 32 & 10 anos & AHGA* \\
3 & 35 & 5 anos & Insulina \\
4 & 38 & 10 anos & AHGA* \\
${ }^{*}$ AHGA - antihiperglicemiante oral. & &
\end{tabular}

O anticorpo antifosfolípides encontrado em três das gestantes foi anticoagulante lúpico. Apenas uma gestante tinha anticorpo anticardiolipina presente e apresentava como antecedente pessoal trombose venosa profunda.

Para o tratamento dos anticorpos antifosfolípides foram propostos a heparina e o ácido acetilsalicílico (protocolo de assistência à gestante com trombofilias - Pré-natal Especializado CAISM/UNICAMP). Apenas uma gestante não recebeu este tratamento, pois o diagnóstico foi realizado periparto. Duas das gestantes apresentaram hipertensão, mas apenas uma delas necessitou de medicação para controle.

Observa-se que a idade gestacional do parto variou de 37 a 39 semanas. Duas das quatro gestantes tiveram recém-nascidos adequados para a idade gestacional, uma delas teve um grande para a idade gestacional e a outra gestante teve recémnascido pequeno para a idade gestacional.

Nenhum dos recém-nascidos apresentou malformação e não houve morte perinatal, mas três deles apresentaram hipoglicemia nas primeiras horas de vida. Três recém-nascidos apresentaram sofrimento fetal intraparto, e dois partos foram vaginais. Todas apresentaram índice de líquido amniótico dentro dos limites da normalidade na ocasião do parto.

Entre as 52 mulheres diabéticas sem anticorpos antifosfolípides a média de idade foi de 26 anos, sendo que $35 \%$ dessas gestantes tinham entre 28 e 33 anos. Dessas gestantes, 43\% tinham diabete gestacional, isto é, quase a maioria da amostra estudada não apresentava doença prévia. Em $32 \%$ o diabete tinha duração menor que cinco anos. Observamos em nosso serviço mulheres com diabete de curta duração ou gestacional.

Mais da metade das gestantes sem anticorpos apresentava 2 ou 3 gestações. As gestantes diabéticas sem anticorpos antifosfolípides apresentam em 60,3\% índice de liquido amniótico nor- 
mal, ao passo que $32 \%$ apresentaram polidrâmnio e apenas $7,5 \%$ oligoâmnio.

Das gestantes diabéticas sem anticorpos antifosfolípides, $71,6 \%$ não apresentaram hipertensão na gestação. Das mulheres que apresentaram hipertensão, 66,7\% utilizaram droga hipotensora.

Entre as mulheres diabéticas que não apresentavam anticorpos antifosfolípides, a média de idade gestacional na ocasião do parto foi de 38 semanas. Em 52,8\% desta amostra foi o recémnascido grande para a idade gestacional. Um terço dos recém-nascidos das mães deste grupo apresentaram sofrimento fetal ao nascimento. A hipoglicemia ocorreu em 58,4\% dos recém-nascidos (Tabela 3).

Tabela 3 - Características dos recém-nascidos das mulheres diabéticas com anticorpos antifosfolípides.

\begin{tabular}{lccccc}
\hline \multicolumn{6}{c}{ Anticorpos antifosfolípides positivos } \\
Gestante & IG & RN & Peso & Parto & SFA \\
\hline Caso 1 & $39+5$ & AIG & 2.650 & Fórcipe & Sim \\
Caso 2 & $38+5$ & GIG & 4.000 & Cesárea & Não \\
Caso 3 & $37+1$ & AIG & 2.680 & Cesárea & Sim \\
Caso 4 & 38 & PIG & 2.400 & Normal & Sim \\
\hline
\end{tabular}

IG - Idade gestacional.

RN - Recém-nascido.

SFA - Sofrimento fetal agudo.

AIG - Adequado para idade gestacional.

GIG - Grande para idade gestacional.

PIG - Pequeno para idade gestacional.

\section{Discussão}

Em nosso estudo, nas 56 gestantes diabéticas avaliadas a presença de anticorpos antifosfolípides foi de $7 \%$, não chegando a $10 \%$ da amostra inicialmente calculada como suficiente para detectar diferenças significativas. Avaliamos todas as gestantes diabéticas que deram entrada em nosso serviço no período estudado, mesmo as gestacionais, o que poderia ser uma das explicações para a baixa prevalência de anticorpos antifosfolipides. Em estudo recente, a prevalência de anticorpos antifosfolipides em gestantes diabéticas foi de $14 \%$, sendo que foram avaliadas gestantes com diabete tipo I ou tipo $\mathrm{II}^{10}$. Se tivéssemos apenas avaliado as gestantes com diabete com mais de 5 anos de evolução, a nossa prevalência aumentaria para $12 \%$. Em função do pequeno número de casos positivos com anticorpos antifosfolipides, passamos a descrevê-los.

As quatro gestantes apresentavam mais de 5 anos de duração do diabete melito e tinham entre 27 e 38 anos. Na literatura observamos que estes eventos tromboembólicos podem estar asso- ciados a complicações vasculares, devido ao maior tempo de duração do diabete e/ou à associação com anticorpos antifosfolípides ${ }^{11,18}$.

A incidência de anticorpos antifosfolípides na população de gestantes é de 5,3\%,37\% em mulheres com lúpus erimatoso sistêmico e $28 \%$ em mulheres com aborto espontâneo recorrente ${ }^{22}$. Entre as diabéticas, no entanto, a freqüência varia muito. Num estudo no qual foram incluídas 35 gestantes com diabete pré-gestacional, a prevalência de anticorpos antifosfolípides foi de 34\%. Por outro lado, em outro estudo observou-se que em gestantes com as mesmas características a prevalência foi de $14 \%$.

O recomendado para o tratamento de anticorpos antifosfolipides em gestantes diabéticas, na literatura, é a associação de heparina e ácido acetilsalicílico em baixas doses ${ }^{11}$. Os melhores resultados gestacionais e perinatais foram obtidos quando as pacientes portadoras destes anticorpos presentes na gestação foram tratados ${ }^{23}$.

Neste estudo realizamos busca exploratória de prevalência com o objetivo de estabelecer uma estratégia de investigação para os eventos desfavoráveis associados à gestação em mulheres com diabete melito, particularmente nos casos com mais tempo de evolução da doença. Nestes casos podem estar envolvidos fenômenos não diretamente relacionados ao controle metabólico. Os casos positivos receberam tratamento conforme proposto para portadoras de anticorpos antifosfolípides na gestação, independente da associação com outra doença.

Apesar de uma casuística pequena, concluimos que para o tratamento de mulheres com diabete melito de longa duração ou com vasculopatia deve ser investigada a presença dos anticorpos antifosfolipides e, se positiva, o tratamento durante a gestação pode melhorar os resultados gestacionais e perinatais.

\section{Referências}

1. Dias EP. Consenso sobre diabetes gestacional. Arq Bras Endocrinol Metab. 1999;43(2):148-9.

2. American Diabetes Association. Diagnosis and classification of diabetes mellitus. Diabetes Care. 2005;28 Suppl 1:S37-42.

3. Jensen DM, Damm P, Moelsted-Pederson L, Ovesen P, Westergaard JG, Moeller M, et al. Outcomes in type 1 diabetic pregnancies: a nationwide, populationbased study. Diabetes Care. 2004;27(12):2819-23.

4. Lepercq J, Taupin P, Dubois-Laforque D, Duranteau L, Lahlou N, Boitard C, et al. Heterogeneity of fetal 
growth in type 1 diabetic pregnancy. Diabetes Metab. 2001;27(3):339-44.

5. Sweeney AT, Brown FM. Gestational diabetes mellitus. Clin Lab Med. 2001;21(1):173-92.

6. Vaarasmaki M, Anttila M, Pirttiaho H, Hartikainen AL. Are recurrent pregnancies a risk in type 1 diabetes? Acta Obstet Gynecol Scand. 2002;81(12):1110-5.

7. Clausen TD, Mathiesen E, Ekbom P, Hellmuth E, Mandrup-Poulsen T, Damm P. Poor pregnancy outcome in women with type 2 diabetes. Diabetes Care. 2005;28(2):323-8.

8. Sibai BM, Caritis S, Hauth J, Lindheimer M, VanDoorsten JP, MacPherson C, et al. Risks of preeclampsia and adverse neonatal outcomes among women with pregestational diabetes mellitus. National Institute of Child Heath and Human Development Network of Maternal-Fetal Medicine Units. Am J Obstet Gynecol. 2000;182(2):364-9.

9. Vaarasmaki M Gissler M, Ritvanen A, Hartikainen AL. Congenital anomalies and first life year surveillance in type 1 diabetic births. Diabet Med. 2002;19(7):589-93.

10. Palomo IG, Mujica VE, Alarcon ML, Pereira JG, Vasquez MR. Prevalence of antiphospholipid antibodies is not different in Chilean diabetic patients and normal individuals. J Diabetes Complications. 2005;19(3):133-7.

11. Boddi M, Prisco D, Fedi S, Cellai AP, Liotta AA, Parretti E, et al. Antiphospholipid antibodies and pregnancy disorders in women with insulin-dependent diabetes. Thromb Res. 1996;82(3):207-16.

12.Lockshin MD, Qamar T, Levy RA. Anticardiolipin and related antibodies: thrombosis and fetal death. In: Scott JS, Bird HA, editors. Pregnancy, autoimmunity and connective disorders. New York: Oxford University Press; 1990. p. 185- 211.

13.Wilson WA, Gharavi AE, Piette JC. International classification criteria for antiphospholipid syndrome: synopsis of a post-conference workshop held at the Ninth International (Tours) aPL Symposium. Lupus. 2001;10(7):457-60.
14. Triplett DA. Obstetrical complications associated with antiphospholipid antibodies. In: Coulam CB, Faulk WP, McITyre JA, editors. Immunological obstetrics. London: Norton Medical Books; 1992. p. 377- 403.

15. Galtier-Dereure F, Biron C, Vies M, Bourgeois V, Schved JF, Bringer J. Vascular complications of diabetes mellitus: what role for phospholipid-binding antibodies? Lupus. 1998;7(7):469-74.

16. Uszynski M, Uszynski W. Antiphospholipid syndrome in obstetrics-a new version of criteria, pathomechanism and the prophylaxis. Ginekol Pol. 2002;73(6):553-66.

17. Kdous M, Hachicha R, Lombroso R, Gallardo G. Antiphospholipid antibodies and pregnancy. Tunis Med. 2005;83(1):1-5.

18.Best IM, Anyadike NC, Bumpers HL. The antiphospholipid syndrome in a teenager with miscariages, thromboses, and diabetes mellitus. Am Surg. 2000;66(8):748-50.

19. Venkat-Raman N, Backos M, Teoh TG, Lo WT, Regan L. Uterine artery Doppler in predicting pregnancy outcome in women with antiphospholipid syndrome. Obstet Gynecol. 2001;98(2):235-42.

20.Huong D1, Wechsler B, Bletry O, Vauthier-Brouzes D, Lefebvre G, Piette JC. A study of 75 pregnancies in patients with antiphospholipid syndrome. J Rheumatol. 2001;28(9):2025-30.

21.Nash MJ, Camilleri RS, Liesner R, Mackie LJ, Machin SJ, Cohen H. Paradoxical association between the 316 Trp to Ser beta 2-glycoprotein I (Beta2GPI) polymorphism and anti-Beta2GPI antibodies. Br J Haematol. 2003;120(3):529-31.

22. Giusti C. Are phospholipid-binding antibodies implicated in the pathogenesis of diabetic microangiopathy? Med Hypotheses. 2004;63(2):2358.

23. Noble LS, Kutteh WH, Lashey N, Franklin RD, Herrada J. Antiphospholipid antibodies associated with recurrent pregnancy loss: prospective, multicenter, controlled pilot study comparing treatment with low-molecular-weight heparin versus unfractionated heparin. Fertil Steril. 2005;83(3):68490. 